\title{
Direct Torque Control with Adaptive PI Speed Controller based on Neural Network for PMSM Drives
}

\author{
Jia, Zhenyu' ${ }^{1}$, Kim, $^{\text {Byeongwoo }}{ }^{2}$ \\ ${ }^{1}$ University of Ulsan, School of Electrical Engineering, 44610 Ulsan, South Korea \\ ${ }^{2}$ University of Ulsan, School of Electrical Engineering, 44610 Ulsan, South Korea
}

\begin{abstract}
This paper presents an adaptive speed controller based on artificial intelligent technique to improvethe performance of classical Direct Torque Control (DTC) for Permanent Magnet Synchronous Motor (PMSM) drives. The proposed method applies back propagation (BP) based neural network (NN) to tune the parameters of classical proportional-integral (PI) speed controller. Comparisons between conventional PI speed controller and proposed method are carried out by Simulation. Simulation results demonstrate that conventional DTC system based on the proposed NN speed controller can achieve higher performance with fast speed response, small overshoot and robustness.
\end{abstract}

\section{Introduction}

Permanent magnet synchronous motors (PMSM) have become more popular in high-performance industrial drives. PMSMs have many advantages, such as high efficiency and power density, high torque-to-inertia ratio and simple structure. The main disadvantage of PMSMs is that flux and torque are inherent coupling, which makes them hard to control. Many advanced control theories have been proposed to make PMSMs more comparable.Filed-oriented control (FOC) [1] and direct torque control (DTC) [2] are the two main control techniques for PMSM drives. The FOC technique is widely used in PMSM drives. However, it performs not as well as predicted in practical engineering application due to the variations of motor parameters and inaccurate control mode [3]. In 1980s, DTC algorithm [4] was firstly introduced from ABB for induction motor drives.Decades past, it was already developed and used for variety of motor drives.

Compared with FOC, DTC is a significantly new concept.It possesses many characteristics of less dependence on machine parameters, fast dynamic response and less complexity without coordinate transformation or current regulation[5]. Classical DTC approach usually adopts a proportional-integral (PI) speed controller, torque and flux hysteresis controllers, and heuristic switching table for generating a variable switching frequency. Consequently, it can cause improper transient response with high overshoot, as well as high torque and flux ripples when applied to PMSM drives.

To solve the aforementioned problems of conventional DTC, varieties of optimization methods have been presented in the literature [6-10]. Many of them can obtain better results in ripple reduction and fixed switching frequency. However, most of them focus on replacing hysteresis controllers [6,9], adopting space vector modulation (SVM) [7] and incorporating multilevel converter [8], thus adding more complexity, computational burden, or hardware cost to DTC system.

Speed controller, usually been neglected, also plays an important role in DTC technique for PMSM drives. A PI controller is widely applied to in the outer speed regulator loop due to its relative simple implementation and effectiveness [11]. However, the PI control approach cannot perform sufficiently well in nonlinear PMSM drives system with various uncertainties [12].Moreover, it's time consuming and hard to tune the proportional and integral gain parameters of PI controller. Recently, some new methods have been proposed to replace PI speed controller $[10,12]$. In [10], artificial neural network (ANN) based on Kalman filter is used as speed controller. Although it can get better simulation results than conventional PI speed controller, it is relatively more complex by combining ANN and Kalman filter. Moreover, it lacks rapidity and stability compared with PI controller.

In this paper, a novel adaptive speed controller based on neural network PI (NN-PI) is presented. Neural network, which is capable of approaching to any nonlinear systems with uncertainties, is applied to tune PI parameters [13].Effective DTC control for PMSM drives can be obtained by optimizing PI controller parameters using NN with nonlinear self-adaptive ability. Simulation results demonstrate that proposed NN-PI speed controller can enhance the operating performance with faster transient response, smaller overshoot, better robustness, 
and even smaller torque and flux ripples compared with classical PI controller based DTC scheme.

\section{Direct Torque Control}

The basic principle of DTC is to select the optimal voltage vectors, which makes the stator flux linkage space vector rotates to required position while keeping magnitude within the hysteresis band and generate desired torque [10].

The speed controller uses the errors between reference speed and estimated speed as inputs to generate reference torque. In this paper, a NN-PI speed controller is applied to improve performance, which will be introduced in next part. The torque hysteresis and flux hysteresis controllers respectively correct errors between the set reference and estimated values to determine the outputs of proper operations in the closed loop [7]. These outputs, together with the information of the position of stator flux linkage space vector, will make the switching table generate corresponding switchingstates $\boldsymbol{S}_{\boldsymbol{a} \boldsymbol{b c}}$ of the voltage inverter [8]. An appropriate voltage vector will be decided based on the switching information.

The relationship between three phase stator voltages $\boldsymbol{V}_{\boldsymbol{s a b c}}$ and switching states can be described as (1):

$$
\boldsymbol{V}_{\boldsymbol{s a b c}}=\left[\begin{array}{l}
V_{s a} \\
V_{s b} \\
V_{s c}
\end{array}\right]=\frac{U_{d c}}{3}\left[\begin{array}{ccc}
2 & -1 & -1 \\
-1 & 2 & -1 \\
-1 & -1 & 2
\end{array}\right]\left[\begin{array}{l}
S_{a} \\
S_{b} \\
S_{c}
\end{array}\right]
$$

Where $U_{d c}$ is DC-bus voltage.

Applying Clark transformation, the $\alpha-\beta$ components of stator voltage space vector in stationary reference frame are obtained as (2):

$$
\left[\begin{array}{l}
V_{\alpha} \\
V_{\beta}
\end{array}\right]=\sqrt{\frac{2}{3}}\left[\begin{array}{ccc}
1 & -0.5 & -0.5 \\
0 & \sqrt{3} / 2 & -\sqrt{3} / 2
\end{array}\right] \boldsymbol{V}_{\text {sabc }}(2)
$$

The DTC scheme works based on control of stator flux linkage space vector, which is estimated in $\alpha-\beta$ reference frame in (3) and (4):

$$
\begin{array}{r}
\psi_{\alpha}=\int\left(V_{\alpha}-R_{s} i_{\alpha}\right) d t \\
\psi_{\beta}=\int\left(V_{\beta}-R_{s} i_{\beta}\right) d t
\end{array}
$$

Where $\psi_{\alpha}$ and $\psi_{\beta}$ are the $\alpha$ - and $\beta$ - axis components of the estimated stator flux linkage, respectively. $i_{\alpha}$ and $i_{\beta}$ are the $\alpha-\beta$ components of stator current space vector. $R_{S}$ is stator resistance.

The magnitude of stator flux linkage and electromagnetic torque are calculated by following equations (5), (6):

$$
\begin{aligned}
& \left|\psi_{s}\right|=\sqrt{\psi_{\alpha}^{2}+\psi_{\beta}^{2}}(5) \\
& T_{e}=\frac{3}{2} P\left(\psi_{\alpha} i_{\beta}+\psi_{\beta} i_{\alpha}\right)(6)
\end{aligned}
$$

Where $\mathrm{P}$ is the number of pole pairs.

\section{Neural Network-PI Controller}

Inspired by the marvellous function of neurons, the artificial neural network (ANN) has been developed very fast to solve big scale and complex problems recently. Numerous works [13-15] have demonstrated that ANN is suitable for dynamic and nonlinear control systems due to the capability of processing, analysing and learning. The speed controller of DTC structure is a nonlinear system, which hasdisturbances of load inertia and motor parametersvariation against temperature [12]. This makes it difficult for PI speed controller to perform sufficiently well for this DTC control system. This paper proposes an adaptive speed controller based on back propagation (BP) neural network, which is verified by simulation with higher performances.

\subsection{Incremental PI Controller}

The PI control theory has been one of the most widely used methods in industrial application. In continuoustime, the PI equation is expressed in (7). When the sampling period is very small, a discrete-time PI controller can be obtained as (8) by replacing integrate with summation and replacing derivative with difference quotient of (7).

$$
\begin{aligned}
& \mathrm{u}(\mathrm{t})=k_{p}\left(e(t)+\frac{1}{T_{i}} \int_{0}^{t} e(\tau) d \tau\right)(7) \\
& \mathrm{u}(\mathrm{k})=k_{p}\left(e(k)+\frac{T}{T_{i}} \sum_{j=0}^{k} e(j)\right)(8)
\end{aligned}
$$

Where $\mathrm{u}(\mathrm{t})$ and $\mathrm{u}(\mathrm{k})$ are controller outputs at continuoustime $\mathrm{t}$ and discrete-time $\mathrm{k}$, respectively; $e(t)$ and $e(k)$ represent tracking errors at continuous-time $\mathrm{t}$ and discrete-time $\mathrm{k}$, respectively; $k_{p}$ is proportional gain; $T_{i}$ is integral time constant; $\mathrm{T}$ is the sampling period. For convenience of program coding work, the equation (8) can be described as incremental form as (9) [15]:

$$
\begin{aligned}
\Delta \mathrm{u}(\mathrm{k})= & \\
& k_{p}(e(k)-e(k-1))+k_{i} e(k)(9)
\end{aligned}
$$

Where $k_{i}$ is the integral parameter gain.

\subsection{Structure of NN-PI Speed Controller}

The NN-PI speed controller using error back propagation (BP) algorithm consists of two parts. One is classical PI controller which can regulate motor speed in the closed loop. The other is BP neural network which can tune the parameters of $k_{p}$ and $k_{i}$ online to achieve the optimal performance. The schematic structure of NN-PI speed controller is shown as in figure 1 . 


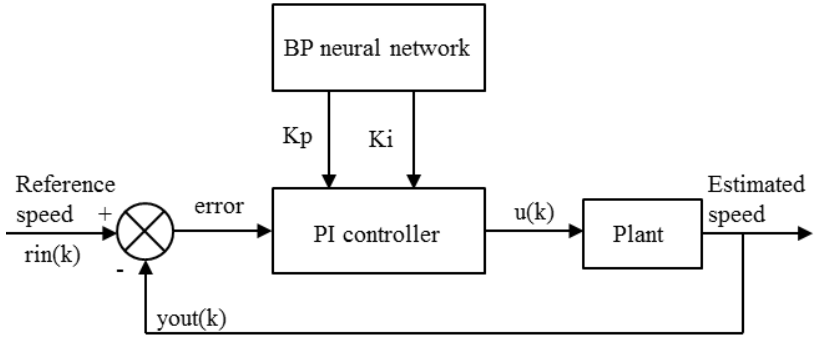

Figure 1. The structure of NN-PI speed controller.

The adopted BP neural network has three-layer, which is described as in figure 2. The numbers of neural nodes of input layer, hidden layer and output layer is $\mathrm{J}$, I and 2, respectively. The inputs are the selected running states of system. The outputs are the parameters of PI controller.

As shown in figure 2, the neuron $\mathrm{i}$ of hidden layer at $\mathrm{k}$ can be expressed by following equations (10), (11):

$$
\begin{aligned}
O_{i}^{(2)}(k) & =f\left(\operatorname{net}_{i}^{(2)}(k)\right)(10) \\
\operatorname{net}_{i}^{(2)}(k) & =\sum_{j=1}^{J} w_{i j}^{(2)} O_{j}^{(1)}(11)
\end{aligned}
$$

Wherenet ${ }_{i}^{(2)}(k)$ and $O_{i}^{(2)}$ denote the input and output of neuron $\mathrm{i}$, respectively; $w_{i j}^{(2)}$ denotes the connection weight parameter between $j^{\text {th }}$ and $i^{\text {th }}$ neurons; $O_{j}^{(1)}$ is the input the $j^{\text {th }}$ neuron; $\mathrm{f}(\mathrm{x})=$ tanh( (x) istangent hyperbolic activation function. Similarly, the output $O_{l}^{(3)}(k)$ and input $n e t_{l}^{(3)}(k)$ of output layer are given by equations (12), (13).

$$
\begin{gathered}
O_{l}^{(3)}(k)=g\left(\operatorname{net}_{l}^{(3)}(k)\right) \quad l=1,2(12) \\
n e t_{l}^{(3)}(k)=\sum_{i=1}^{I} w_{l i}^{(3)} O_{i}^{(2)}(13)
\end{gathered}
$$

Where $g(x)=1 / 2(1+\tanh (x))$ is the activation function of output layer.

The weights are updated using gradient descent method based on BP algorithm, which is given by (14):

$$
\Delta \mathrm{w}(\mathrm{k})=-\eta \frac{\partial E(k)}{\partial w}+\alpha \Delta w(k-1)
$$

Where $\mathrm{E}(\mathrm{k})=1 / 2(\operatorname{rin}(k)-\operatorname{yout}(k))^{2}$ is cost function, $\eta$ is learning rate, $\alpha$ is momentum rate. The weights updating equations are given as follows:

$$
\begin{aligned}
& \Delta w_{l i}^{(3)}(k)=\alpha \Delta w_{l i}^{(3)}(k-1)+\eta \delta_{l}^{(3)} O_{i}^{(2)}(k)(15) \\
& \Delta w_{i j}^{(2)}(k)=\alpha \Delta w_{i j}^{(2)}(k-1)+\eta \delta_{i}^{(2)} O_{j}^{(1)}(k)(16)
\end{aligned}
$$

Where $\delta_{l}^{(3)}=\operatorname{error}(k) \frac{\partial y(k)}{\partial u(k)} \frac{\partial u(k)}{\partial o_{l}^{(3)}(k)} g^{\prime}\left(\operatorname{net}_{l}^{(3)}(k)\right)$ and $\delta_{i}^{(2)}=f^{\prime}\left(\operatorname{net}_{i}^{(2)}(k)\right) \sum_{l=1}^{2} \delta_{l}^{(3)} w_{l i}^{(3)}(k)$.

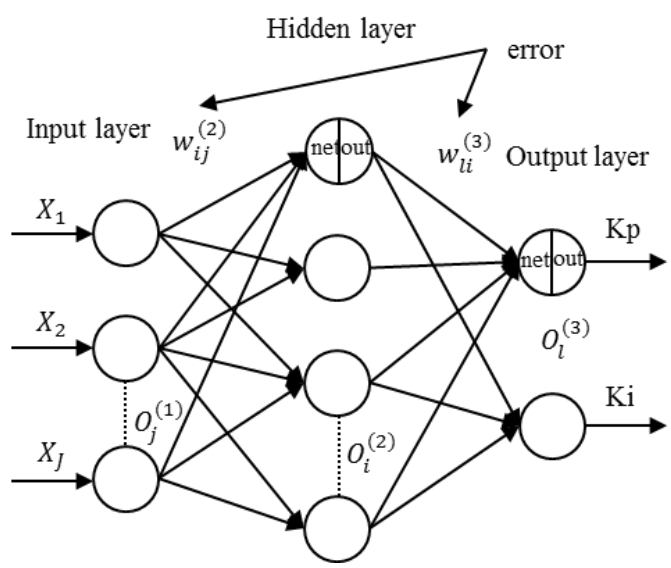

Figure 2. The structure of BP neural network.

\section{Simulation and Results}

The proposed method is evaluated by simulation on MATLAB.The parameters of PMSM drive system considered in this study are listed in Table 1.

Table1. Simulation parameters of PMSM.

\begin{tabular}{|c|c|}
\hline Parameter & Values \\
\hline Number of pole pairs $\mathrm{P}$ & 4 \\
\hline Stator resistance $R_{s}$ & $1.2 \Omega$ \\
\hline Magnet flux linkage & $0.175 \mathrm{~Wb}$ \\
\hline d-axis inductance $L_{d}$ & $8 \mathrm{mH}$ \\
\hline q-axis inductance $L_{q}$ & $8.5 \mathrm{mH}$ \\
\hline Moment inertia $\mathrm{J}$ & $0.0008 \mathrm{~kg} \cdot \mathrm{m}^{2}$ \\
\hline Viscous friction $\mathrm{F}$ & $0.0001(\mathrm{~N} . \mathrm{m} . \mathrm{s})$ \\
\hline
\end{tabular}

To demonstrate the performance of the presented NN-PI speed controller, the simulation results for a classical PI speed controller and the NN-PI speed controller are compared. The simulation model of proposed method is shown in Figure 3. Both of the methods are tested under same conditions with reference speed, load torque reference and simulation settings.

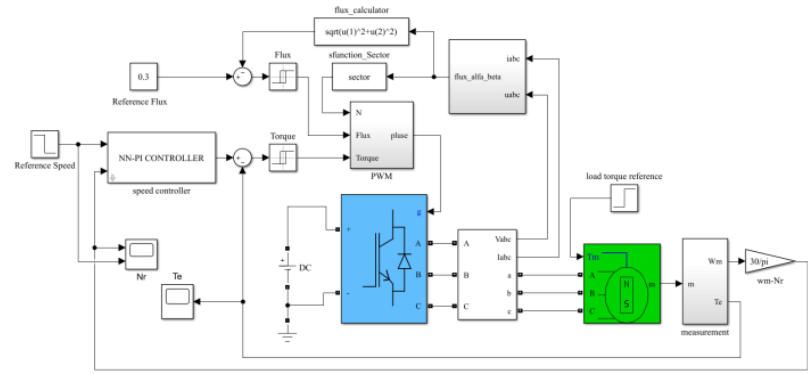

Figure 3. Simulation model of DTC system for PMSM drives with NN-PI speed controller.

The simulation is start at the speed on $600 \mathrm{r} / \mathrm{min}$ with a constant load torque $1.5 \mathrm{~N}$ applied at $0.2 \mathrm{~s}$ and sudden 
speed reduction to $550 \mathrm{r} / \mathrm{min}$ at $0.35 \mathrm{~s}$. The simulation results of speed respond are shown in Figure 4 and 5.

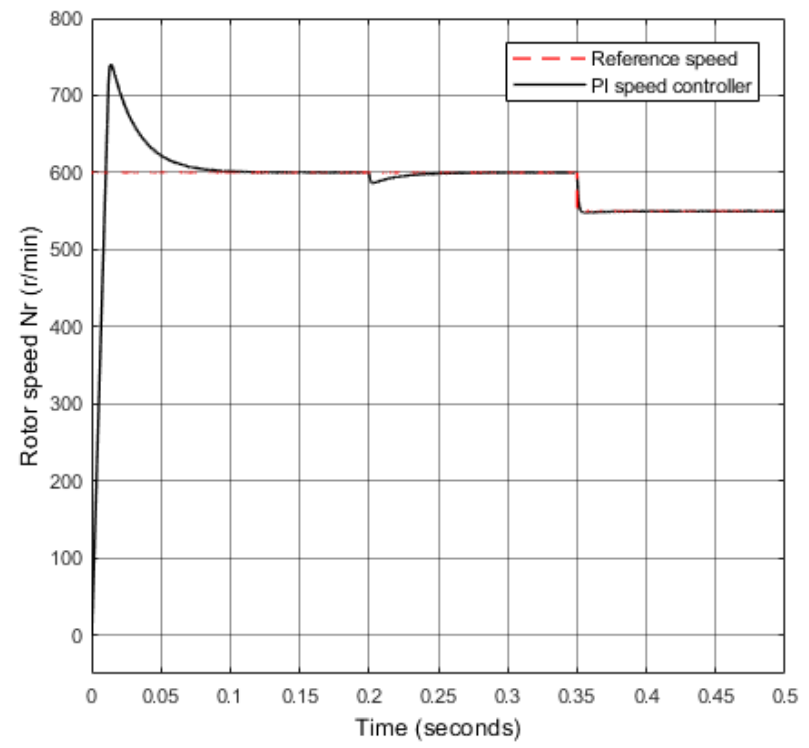

Figure 4. Speed response of conventional DTC system with PI speed controller.

It's clearly shown that the proposed method obtains great improvement in reduction of overshoot at the start-up period. Moreover, NN-PI speed controller has much better speed tracking performances than PI controller when facing load torque variations and sudden speed change.

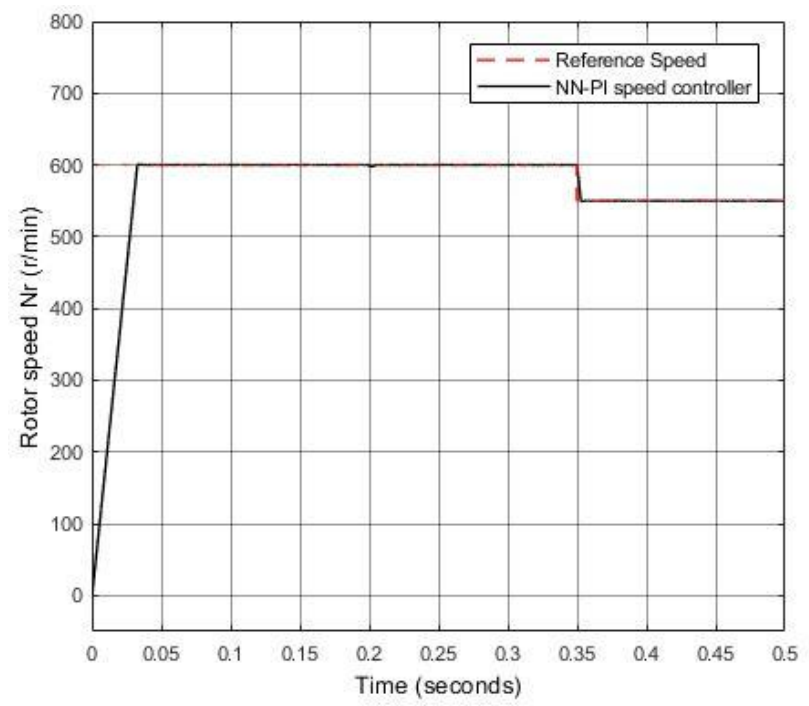

Figure 5. Speed response of conventional DTC system with NN-PI speed controller.

The comparison of Electromagnetic torque responses between conventional DTC system with PI controller and proposed DTC system with NN-PI controller is shown in Figure 6. As can be seen, the proposed method also get relatively better resultwith lower pulse and faster dynamic response in start-up period. Moreover, NN-PI also performs more stable under sudden load torque variationand speed reduction.

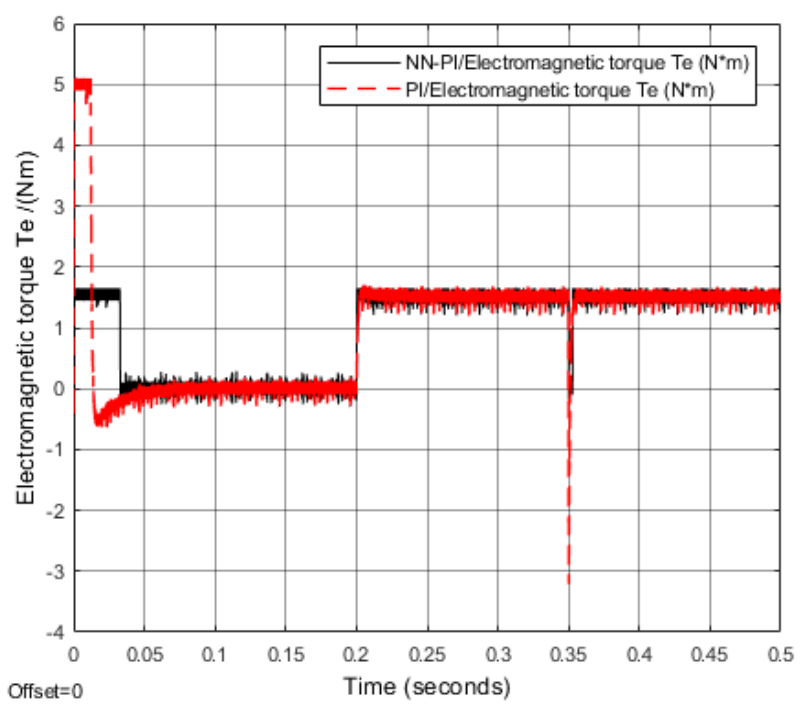

Figure 6. The response of electromagnetic torque of PI controller and NN-PI controller.

Figure 7 shows the flux response of both methods. It seems there is no big improvement. The proposed method can obtain stable flux response with small flux ripples under some system uncertainties.
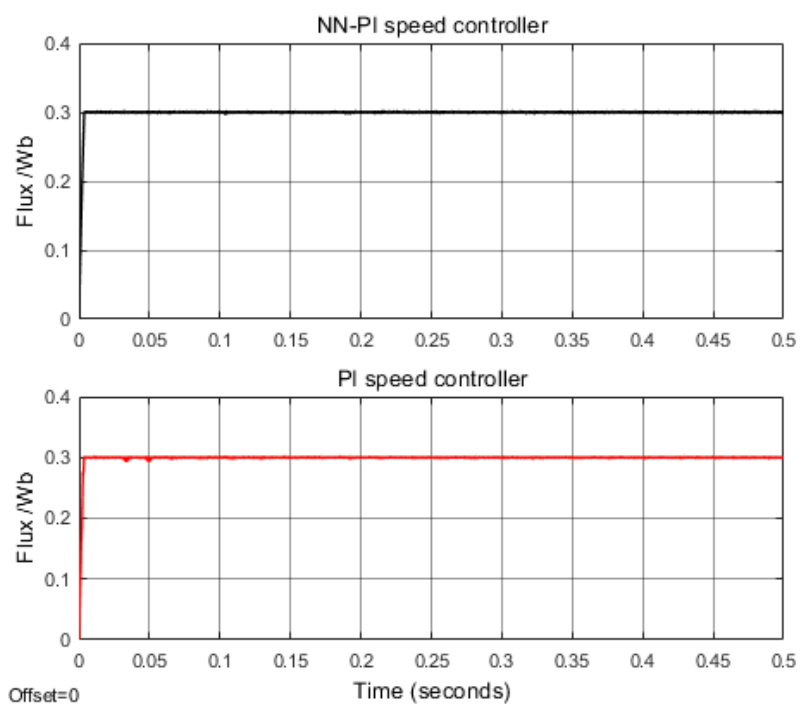

Figure7. The response of flux of NN-PI and PI controllers.

\section{Conclusions}

In this paper, an adaptive speed controller using BP neural network for DTC technique based PMSM drives is designed. BP neural network is applied to tune parameters of PI speed controller, which overcomes the disadvantages of conventional PI controller with high dependence on controlled model and time-consuming tuning work.

The simulation results demonstrate the effectiveness of the proposed NN-PI speed controller with faster response, 
much smaller overshoot and better robustness compared to conventional PI controller.

Further work will be concentrated on torque ripple reduction by more advanced theory.

\section{ACKNOWLEDGEMENTS}

I express my sincere gratitude towards my professor, Kim, Byeongwoo, for his supports; I am grateful to my colleagues for their helps.

The research was supported by the Industry Core Technology Development Project "Development of $2 \mathrm{~kW} / \mathrm{kg}, 100 \mathrm{~kW}$ class IPMSM electric drive system with high efficiency cooling" through the Ministry of Trade, Industry and Energy (Grant Number : 10063006).

\section{References}

1. Ke Song, Wei guo Liu."Permanent Magnet Synchronous Motor Field Oriented Control and HIL Simulation," IEEE Vehicle Power and Propulsion Conference, Harbin, pp.4-6.(2008)

2. M. F. Rahman, L. Zhong, E. Haque, and M. A. Rahman, "A Direct Torque-Controlled Interior Permanent-Magnet Synchronous MotorDrive Without a Speed Sensor,'IEEE Trans. Energy conversion, vol. 18, no. 1, (2003)

3. A. Haddoun, M.E.H Benbouzid, D. Diallo, R. Abdessemed, J. Ghouili, K.Srairi, "A lossminimization DTC scheme for EVinduction motors," IEEE Conference Vehicle Power andPropulsion. pp. $7(2005)$

4. I. Takahashi, T. Noguchi, “A new quick-response and high-efficiency control strategy of an induction motor," IEEE Trans. Ind. Appl, IA-22(5), 820-827 (1986)

5. W. Jiajia, G. Dawei, Z. Xin, L. Qingchun, "An efficiency optimization strategy of induction motors for electric vehicles," IEEE Vehicle Power and Propulsion Conference, pp, 1-5. (2008)

6. Y. Choi, H. Choi, and J. Jung, "Feedback linearization direct torque control with reduced torque and flux ripples for IPMSM drives,"IEEE
Trans. Power Electron., vol.31, no. 5, pp. 3728-3737 (2016)

7. L. Tang, L. Zhong, M. F. Rahman, and Y. Hu, "A novel direct torque controlled interior permanent magnet synchronous machine drive with low ripple in flux and torque and fixed switching frequency," IEEE Trans. Power Electron., vol. 19, no. 2, pp. 346354, ( 2004)

8. C. A. Martins, X. Roboam, T. A. Meynard, and A. S. Carvalho, "Switching frequency imposition and ripple reduction in DTC drives by using a multilevel converter," IEEE Trans. Power Electron., vol. 17, no. 2, pp. 286-297, (2002)

9. Y. Cho, K.-B. Lee, J.-H. Song, and Y.-I. Lee, "Torque-ripple minimization and fast dynamic scheme for torque predictive control of permanentmagnet synchronous motors," IEEE Trans. Power Electron., vol. 30, no. 4, pp. 2182-2190, (2015)

10. F.Hamidia, MS.Boucherit, A.Larabi, M.Bouhedda, "Direct Torque Control with ANN Speed Controllerbased on Kalman filter for PMAM", IEEE Trans, 9th International Conference on Systems, Signals and Devices, (2012)

11. Y. Su, C. Zheng, and B. Duan, "Automatic disturbances rejection controller for precise motion control of permanent-magnet synchronous motors," IEEE Trans. Ind. Electron., vol. 52, no. 3, pp. 814823, ( 2005)

12. S. Li and Z. Liu, "Adaptive speed control for permanent magnet synchronous motor system with variations of load inertia," IEEE Trans. Ind. Electron., vol.56, no. 8, pp. 3050-3059, (2009)

13. H. Ji and Z. Li, Design of Neural Network PID Controller Based on Brushless DC Motor, Second International Conference on Intelligent Computation Technology and Automation, Vol.3, pp.46-49, ( 2009)

14. Sigeru Omatu, Michifumi Yoshioka, Toshihisa Kosaka and Hidekazu Yanagimoto, Neuro-PID Control of Speed and Torque of Electric Vehicle, International Journal on Advances in Systems and Measurements, vol. 3, no. 1-2, (2010).

15. J. Kang, W.J. Meng, A. Abraham, H.B. Liu, An adaptive PID neural network for complex nonlinear system, Neurocomputing 135, 79-85.(2014) 